\title{
AN UNUSUAL CASE OF RESPIRATORY OBSTRUCTION
}

\author{
BASIL SKINNER, M.D. *
}

AN OBESE Negro wOMAN, aged 44 years, weighing 198 lbs., was admitted to a surgical ward of the Queen Elizabeth Hospital, Barbados, because of a large, non-toxic, benign goitre, and respiratory obstruction which completely prevented sleeping in the recumbent position, and caused severe respiratory distress even when awake.

Examination of the patient revealed: (1) a very large goitre; (2) gross tracheal displacement to the right side; (3) severe respiratory distress, especially when recumbent; (4) high-pitched breath sounds on auscultation over the right side of the neck, extending about three inches below the right clavicle, indicative of severe narrowing of the airway; (5) the patient's neck was freely mobile, and easily extendible at the atlanto-occipital joint.

Soft tissue X-rays of the neck and thorax revealed: (1) gross displacement of the trachea to the right: (2) severe narrowing of the trachea, starting at the level of C6, and extending down as far as T5 (Fig. 1). Since the centre-beam of the X-ray was centred over the region of $\mathrm{C} 5-\mathrm{C} 6$, some distortion must be allowed for, and the actual narrowing of the trachea most probably did not extend beyond T4; (3) a large extension of the tumour retrosternally (Fig. 1).

Preoperative tracheostomy was considered, but was deemed impossible due to the size and position of the tumour. It was thought that the induction of anaesthesia in the normal way might be extremely hazardous, because obstruction of the airway would be likely to become complete with loss of conscious control, and if this were to be followed by difficulty in intubation, a dangerous situation would arise. The patient was, therefore, intubated in the conscious state, and this was accomplished as follows.

Premedication was Omnopon gr. 1/3 and Scopolomine gr. 1/150. Thirty minutes later the patient was brought to the induction room, and was made to gargle with, and swallow part of, $6 \mathrm{ml}$. of Anethane 2 per cent (Amethocaine). The larynx and upper trachea were sprayed with 4 per cent Lignocaine, using a Macintosh spray. Ten per cent cocaine was applied to the pyriform fossae using a gauze swab, on the end of Kraus' forceps.

The patient was then made to lie down, and was moved to the surgical table. An intravenous infusion of 5 per cent dextrose in water was set up, and laryngoscopy was attempted with a curved Macintosh laryngoscope blade. It was found that laryngoscopy could only be achieved by passing the blade down the left side of the tongue, and aiming it obliquely at the epiglottis, which was situated well over to the right side of the neck; only the right vocal cord was visualized, due to the oblique angle of view. Apart from this minor difficulty, intubation was accomplished easily with an $8 \mathrm{~mm}$. cuffed Magill endotracheal tube, without any coughing or distress on the patient's part. General anaesthesia was immediately

-Present address: Foothills Hospital, Calgary, Alberta. 


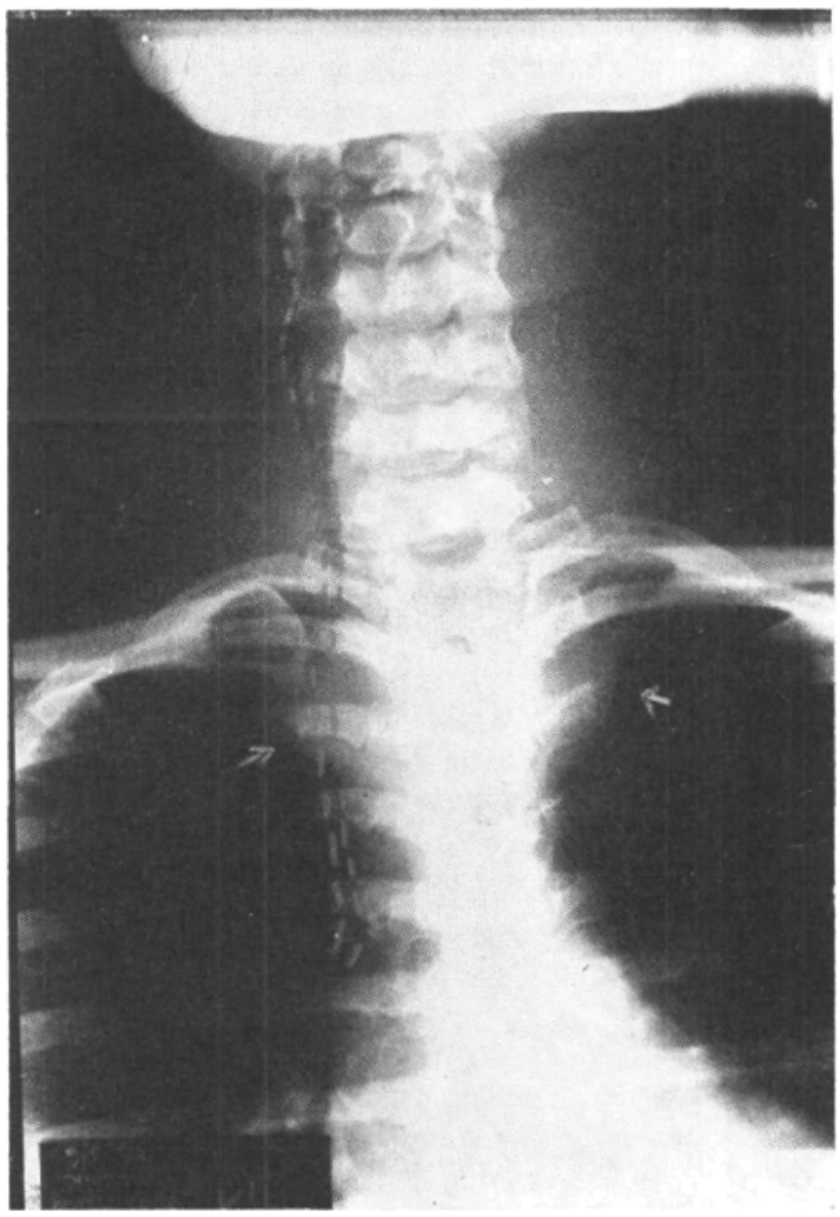

FIcure 1. Antero-posterior X-ray shows position of the trachea displaced to the right side, and also its extreme narrowing (hatched line). The retrosternal part of the tumour can also be clearly seen (arrows).

induced with $300 \mathrm{mg}$. of 2.5 per cent thiopentone followed by $15 \mathrm{mg}$. of succinylcholine, and maintained with nitrous oxide $3 \mathrm{l} . / \mathrm{min}$., oxygen $1.5 \mathrm{~L} / \mathrm{min}$., and $0.1 \%$ succinylcholine by intravenous drip. Ventilation was controlled manually. It was found that pressures in the order of $25-28 \mathrm{~cm}$. of water were necessary to inflate the patient's lungs, and that the degree of obstruction became worse when the patient was placed in the "thyroidectomy" position, with a sandbag under the shoulders and the head and neck hyperextended. However, ventilation appeared to be adequate as far as oxygenation was concerned, although the anaesthetist was suspicious about the possible development of hypercarbia. In view of the urgency of the operation, it was considered that it would be in the best interests of the patient to continue, even if there was a period of hypercarbia prior to the delivery of the tumour with the expected resulting relief of airway obstruction. 
Shortly after the skin incision was made, airway obstruction became complete. The endotracheal tube cuff was deflated, but this made no difference. The patient's head and neck were then flexed, and considerable improvement in the airway ensued, although high pressures were still necessary to achieve adequate ventilation.

It was then thought that the endotracheal tube was becoming either kinked or compressed due to pressures exerted upon it by the tumour in the hyperextended position. Therefore, the tube was replaced by a cuffed reinforced latex Magill tube, and the patient's head and neck were once again hyperextended. Things went reasonably well for a few minutes, but with high ventilatory pressures necessary as before, and the operation was resumed. But now it was noticed that the expiratory phase was becoming severely impeded and prolonged, and it was concluded that the narrowed trachea was draping itself over the end of the endotracheal tube and impeding expiration by a one-way-valve action. Ventilation soon became more difficult, and complete obstruction occurred again. This was relieved once again by flexing the patient's head and neck, and the surgeon was asked to continue with the patient in this position for as long as possible. But after 15 minutes the surgeon reported that further progress was impossible with the head flexed, owing to the large size of the tumour.

It was by then obvious that the only chance of success would be to pass an endotracheal tube beyond the area of tracheal narrowing, i.e., almost to the carina. The latex reinforced tube was then removed, and replaced by a new $6 \mathrm{~mm}$. "streamline" cuffed Magill endotracheal tube. Right endobronchial intubation was performed. Inflation immediately became normal for the first time, and it was clearly seen that the right lung alone was being inflated. The patient's head and neck were then hyperextended once more, and the endotracheal tube slowly withdrawn until ventilation of both lungs was achieved. The tip of the Magill tube was therefore just proximal to the carina. The tube was then carefully taped in position, the patient was redraped, and the operation resumed, with ventilation continuing normally and uneventfully thereafter.

At the end of the operation, the endotracheal tube was removed, and nasotracheal intubation carried out with a $7 \mathrm{~mm}$. "streamline" cuffed Magill tube, which was left in position for 24 hours. The patient awoke from the anaesthetic quickly, and tolerated the nasotracheal tube extremely well.

On the morning following the operation, the patient was brought to the operating room, an intravenous infusion was established and full preparations for general anaesthesia made. Endobronchial toilet was then carried out through the endotracheal tube. At this time, however, the patient was again suffering both inspiratory and expiratory respiratory embarrassment. With the patient sitting up, the Magill tube was slowly removed, after which she was able to breathe normally and freely. Respiration continued without further embarrassment on resumption of the supine position.

Inspection of the endotracheal tube showed a mass of semi-inspissated mucus in its lumen, near the tip, which had defied aspiration, and which was the cause of the patient's respiratory difficulties on the first postoperative morning. 
In spite of four intubations and an indwelling endotracheal tube for 24 hours postoperatively, the only ill effects which the patient suffered were slight hoarseness and a serosanguinous exudate beneath the skin, which was subsequently aspirated with a 16-gauge needle. There was no sepsis in the wound, in spite of the considerable amount of interference with the sterile drapes during the operative procedure. A recent follow-up X-ray examination, taken four and a half months later, shows the trachea to be now completely normal.

\section{Discussion}

It would seem to be advisable to advance an endotracheal tube to the carina in any case where severe tracheal narrowing is known to be present, as an elective procedure, and not to wait until one is forced to do so, as was the case with this patient. Another alternative would be to use one of the double-lumen endotracheal tubes, but the difficulties of intubation in cases of gross tracheal displacement might preclude the use of such a tube when intubation is to be carried out under topical anaesthesia alone.

A valid criticism is that the patient's inspired air was not humidified during the postoperative period, and this undoubtedly contributed to the formation of the mucus plug in the nasotracheal tube. The average relative humidity during that period was 85 per cent, with a low of 80 per cent, and we had previously found it unnecessary to humidify short-term cases of from 12 to 24 hours' duration. This case clearly shows, however, that there is no exception to the rule that indwelling endotracheal and tracheostomy tubes necessitate humidification of the inspired air.

\section{SUMMARY}

A case is reported which illustrates that respiratory obstruction can occur even after successful intubation when large tumours in the neck or mediastinum produce displacement and narrowing of the trachea. A suggestion is made for avoiding such obstruction in future cases.

\section{RÉSUMÉ}

Il s'agit d'un cas qui montre qu'on peut avoir une obstruction respiratoire même après une intubation réussie, lorsque les tumeurs volumineuses $\mathrm{du}$ cou ou $\mathrm{du}$ médiastin déplacent et retrécissent la trachée. On apporte une suggestion pour éviter une telle obstruction à l'avenir. 